\title{
A Walk in the Woods
}

\section{Adlapting Archaeological Training to Archival Discovery}

\author{
Katie Kirakosian and Heidi Bauer-Clapp
}

\section{ON THE PARALLELS BETWEEN THE ARCHAEOLOGICAL RECORD AND ARCHIVAL RECORDS}

Archaeologists are not often trained in archival research techniques, but archaeological training can serve archaeologists quite well when they are conducting archival research thanks to the parallels between the archaeological and archival records. Archivists, like archaeologists, focus on the past. While archaeologists work to carefully undo the archaeological record, archivists compile the archival record. By nature, each record is a nonrenewable cultural resource that is vast, fragmentary, fragile, interpretive, and political (Danielson 2010; Eastwood and MacNeil 2017; Foucault 1972; Ketelaar 2002; Thomassen 2001; Williams 2006). The work of archivists, in the form of collections processing, bears striking resemblance to the work archaeologists do in the field and the lab. This work, however, has been greatly affected by the digital age (Averett et al. 2016; Dobreva and Duff 2015; Eiteljorg 1998; Huggett 2015; McKemmish 2001; Poole 2015; Roosevelt et al. 2015; Tourney 2003).

The building blocks of both disciplines are similar in concepts like context, provenience (or provenance), and stratigraphic sequenc- ing (or original order; see Williams 2006). For both, preservation is also a true concern. Both disciplines have their professional origins in the late nineteenth century and have become increasingly reflexive and critical in response to postmodernism, which, as a result, has led individual archaeologists, like archivists, to be seen as "an active mediator in shaping collective memory" (Cook 2001:24). However, while archivists have been seen as "custodians" of archival records for the purpose of research by others, archaeologists not only collect, process, and analyze, but also interpret the archaeological record (Ketelaar 2002; Schwartz and Cook 2002; Trace 2002).

While archaeologists' prime concern is to ensure the stability of sites, artifacts, and ecofacts, field and laboratory notes, photographs, and administrative records, as well as published and unpublished materials should never be forgotten. Without the latter, the research potential of sites, artifacts, and ecofacts is greatly compromised. It is these materials, we argue, that separate archaeologists from looters (see Bauer-Clapp 2016; Kirakosian 2014). Fowler and Givens (1995:100) concur, admitting, "Collections of artifacts and ecofacts without accompanying documentation are useless." While there has been a decided push in recent decades to digitize archival collections of all types, the percentage of collections that are digitized is small due to

\section{ABSTRACT}

Due to various factors, physical archives of archaeological significance are inconsistent in terms of level of organization and ability to access. In addition, while well-versed in archaeological theory and method, archaeologists are seldom trained in archival theory and method. These factors make it challenging for archaeologists to utilize archival records. Given some unique parallels between archival records and the archaeological record, the authors suggest that archaeological field training can, in fact, serve archaeologists quite well when conducting archival research. While this article focuses mainly on primary sources in physical archives, some discussion of digital archives is included here as well.

Debido a diversos factores, los archivos físicos de importancia arqueológica son inconsistentes en cuanto de su nivel de organización y capacidad de acceso. Aunque tienen conocimientos en la teoría y el método arqueológicos, los arqueólogos no son entrenados típicamente en teoría y método de archivo. Dados algunos similitudes únicos entre los registros de archivo y el registro arqueológico, los autores sugieren que el entrenamiento arqueológico en el campo puede, de hecho, servir a los arqueólogos bien de realizar investigaciones archivísticas. Aunque este artículo se centra principalmente en fuentes primarias en archivos físicos, también se incluye una discusión de archivos digitales. 
budgetary, logistical, and privacy concerns (Gina Rappaport, personal communication 2016). This means that the likelihood that an archaeologist will need to conduct archival research in a physical archive during his/her career is high.

\section{ARCHAEOLOGY'S PAPER TRAIL: WHAT CAN ARCHIVAL MATERIALS CONTRIBUTE TO ARCHAEOLOGICAL RESEARCH?}

Broadly speaking, archaeologists utilize archival records for two main purposes: to better understand specific sites or to establish sociohistorical contexts. Here we provide some key steps in archival research and some examples from our own research. While conducting dissertation research on the history of shell midden archaeology in Massachusetts, Kirakosian consulted archival holdings at five research facilities throughout New England and New York State: the Massachusetts Historical Society, the Robert S. Peabody Museum of Archaeology, the Robbins Museum of Archaeology, the New York State Museum, and the Nantucket Atheneum. While at these facilities, she accessed field notes, laboratory notes, images, newspaper clippings, personal letters, reports, site files, and sketches (Kirakosian 2014). These were instrumental in allowing Kirakosian to begin to reconstruct the social networks of archaeologists through time and to better understand the shell midden sites and excavations selected for her research project.

While conducting research related to repatriation, Bauer-Clapp consulted archival records at Smith College, the University of Massachusetts Amherst, Amherst College, Hamline University, and the American Museum of Natural History, studying field notes, site reports, images, maps, and collection records. She also consulted online digital newspaper collections and military records. Bauer-Clapp and Perez (2014) relied heavily on archival records in a research project investigating whether several sets of human remains (held at the time of study by the American Museum of Natural History [AMNH]) represented individuals killed in a military battle in Mexico or through a massacre by Mexican troops. They consulted military records, newspaper articles describing historical events and the political circumstances of the time, AMNH's catalog records, and the personal journal of Aleš Hrdlička, who collected materials, including the human remains, for the AMNH. Connecting information gleaned from these sources with data from our osteological analysis led us to conclude that the individuals died as a result of a massacre rather than a battle, a conclusion we never could have reached through osteological evidence alone (see Bauer-Clapp and Perez 2014). While conducting dissertation research on St. Helena's Liberated African heritage, Bauer-Clapp also conducted research at the British Library, the Bodleian Library at University of Oxford, and the St. Helena Archives (Bauer-Clapp 2016).

From these research experiences, we acknowledge that it can sometimes be difficult to decipher whether archival records are, in fact, shedding light on a specific site or the sociohistorical context surrounding a site's excavation. In order to focus archival research efforts effectively, it is useful to differentiate between these domains and develop relevant questions within each. To clarify these differences, we have created a series of hypothetical questions to ask when reviewing archival records to help you extract as much meaningful information as possible from the major categories of archival documents of archaeological interest (see Table 1). Archaeologists also use archival research to better understand social, historical, or political contexts beyond the scope of a particular excavation, which impact how archaeological data might be interpreted.

While Gero (1990:114) was quick to point out that archaeologists are "optical empiricists," accessing and viewing primary sources (especially field photos) in the archive can be an important step to understanding earlier archaeological work, as two archaeologists may not see material evidence (e.g., features) in exactly the same way. With this said, it is important to note that a researcher should always turn directly to as many archival sources as possible and not just go to the published reports as the main piece of evidence when trying to understand a given site. Since it is clear that data are interpreted, accessing primary site data becomes necessary for a researcher to interpret anything from an artifact or a feature, to a site, time period, or a region. Doing so allows you to consider evidence with confidence rather than assuming that others' interpretations are unequivocal (see, for example, Claassen 1995; Kirakosian 2014). Indeed, as Silverman (1995:1) explains, when future researchers try to unravel the history of anthropology that continues to be woven every day, it is the records generated by researchers such as "notes, correspondence, and other unpublished items" that will tell the story rather than "condensed and edited information contained in published form."

Fowler and Givens (1995:98) consider there to be four main categories of useful material for understanding archaeological sites: "provenience documentation, analytic documentation, administrative documentation, and project ('published') reports." Local newspapers can also help fill in details about specific sites, as well as "the records of regional and national archaeological societies, the private papers of archaeologists and paleoenvironmentalists, and oral histories relevant to the history of archaeology" (Fowler and Givens 1995:104). Archaeological field and laboratory notes, like all such records, are unique in that they lie somewhere "between observation (or other forms of encounter with the focus of study), the recording of 'data,' interpretation, and writeup" (Silverman 1999; see also Jackson 1990).

As an example, to better understand several excavations from the early 1960s, Kirakosian conducted archival research at the New York State Museum and conducted interviews with several archaeologists that had worked on these sites as graduate students. When comparing the field notes and interview transcripts to the published material on these sites, she was struck by the fact that details about the site that were presented as "facts" were of course open to varying interpretations. For example, while an archaeologist is documenting a fact when noting what was uncovered while excavating a feature, an archaeologist then has to interpret what these findings mean. As such, it is problematic to present the meaning of site data as incontrovertible. This example serves to illustrate why you should be careful when reviewing archival materials to try and better understand archaeological sites. Woven within these sources are theories and researcher impressions in addition to myriad facts. 
TABLE 1. How to Question Archival Materials to Maximize Information Gained.

\begin{tabular}{|c|c|c|}
\hline Archival material type & Questions related to a site's past occupation & $\begin{array}{l}\text { Questions related to the context of the } \\
\text { excavation }\end{array}$ \\
\hline Provenience materials & $\begin{array}{l}\text { What do these data show about a site's use } \\
\text { through time and space? }\end{array}$ & $\begin{array}{l}\text { What were the standards at the time? } \\
\text { Were adequate records kept at the time? }\end{array}$ \\
\hline Analytical materials & $\begin{array}{l}\text { Were all analyses completed? } \\
\text { Are there unprocessed soil samples or carbon } \\
\text { samples, for example? }\end{array}$ & $\begin{array}{l}\text { Should any analyses be redone based on } \\
\text { improved or new techniques? } \\
\text { Is there a revised typology since this site was } \\
\text { initially excavated? }\end{array}$ \\
\hline Administrative materials & $\begin{array}{l}\text { What details in these materials shed light on the } \\
\text { site? } \\
\text { Are there findings, hypotheses, interpretations } \\
\text { that were never published? }\end{array}$ & $\begin{array}{l}\text { Are there details in these materials that shed light } \\
\text { on the excavation's context? }\end{array}$ \\
\hline $\begin{array}{l}\text { Project ("published") } \\
\text { reports }\end{array}$ & $\begin{array}{l}\text { What was found at a site and what was the site's } \\
\text { significance to the researchers? }\end{array}$ & $\begin{array}{l}\text { In what ways might the theories and methods } \\
\text { employed at the time affect the outcomes of } \\
\text { the site excavation? } \\
\text { Were the results compromised because of } \\
\text { improper handling of samples, what were the } \\
\text { research questions, or was there clear } \\
\text { researcher bias? }\end{array}$ \\
\hline Local newspapers & $\begin{array}{l}\text { Are there details about and photos from an } \\
\text { excavation that shed more light on the site? }\end{array}$ & $\begin{array}{l}\text { Are there details and photos that shed more light } \\
\text { on the excavation itself? } \\
\text { Who were the personnel/volunteers on site, was } \\
\text { there public interest/hostility, financial support? }\end{array}$ \\
\hline $\begin{array}{l}\text { Regional/national society } \\
\text { materials }\end{array}$ & $\begin{array}{l}\text { Do these materials contain never before } \\
\text { considered details about a site? }\end{array}$ & $\begin{array}{l}\text { Do these materials contain never before } \\
\text { considered details about an excavation? }\end{array}$ \\
\hline Private papers & $\begin{array}{l}\text { Do private papers contain never before } \\
\text { considered details about a site? } \\
\text { Are there site details found here that shed new } \\
\text { light on a site? }\end{array}$ & $\begin{array}{l}\text { Do private papers contain never before } \\
\text { considered details about an excavation? } \\
\text { Might researcher hostilities or alliances have } \\
\text { affected a field crew? }\end{array}$ \\
\hline Oral histories & $\begin{array}{l}\text { Do personal recollections help illuminate details } \\
\text { about a site's occupation? }\end{array}$ & $\begin{array}{l}\text { Do personal recollections help illuminate details } \\
\text { about a site's excavation? }\end{array}$ \\
\hline
\end{tabular}

Beyond investigating sites or specific excavations, archaeologists may consult archival records in order to better understand the social, political, or historical context within which archaeological materials originated or within which archaeologists were working. Our hope is that through this article and others in this issue, readers see new possibilities for archival research in their own work and feel prepared to take on such research.

As an example from historical archaeology, Shackel (1992) argues for increased use of probate inventories to enhance analysis of material culture or better contextualize data from excavations. Ziegenbein (2013) extends this to position probate records as a source of data in the absence of material culture obtained through excavation. Using detailed lists of material culture recorded in such inventories, she was able to reconstruct the material world of a visually impaired abolitionist who died in 1849. Probate records provide a view into the daily life of a visually impaired individual more nuanced than what could be obtained through excavation. Relatively new clothing, for example, might indicate that the individual died unexpectedly; the absence of a mirror in the individual's bedroom, when mirrors are inventoried in other rooms used by nonvisually impaired individuals, reminds us that material culture is both shaped by and reflective of individual needs (Ziegenbein 2013).
A volume edited by Means (2013a) offers an example of archival research to both better understand individual excavations as well as sociohistorical contexts of those excavations. The authors in this volume utilize archival research to provide a detailed overview of Work Progress Administration (WPA) archaeological projects conducted under the New Deal. While these excavations yielded significant amounts of data, findings from many sites were unreported or underreported. Archival research helped authors understand how WPA archaeological projects were conceived of, organized, and conducted. For example, many WPA workers on these projects had no formal archaeological training, which required standardized ways of collecting data in the field. This led to the development of preprinted data forms (Means 2013b). Authors in Means (2013a) then drew on these "musty and brittle field records" (Means 2013b:2) to bring new attention to findings from unreported or underreported sites.

Finally, we're inspired by an intriguing example from our colleagues in cultural resource management (CRM). Archaeologists working at Archaeological Services at the University of Massachusetts Amherst excavated an Irish tenement dating to the late 1800s in Roxbury, Massachusetts. Material culture recovered from the site included two fragments from a child's slate with the words "Sherwin" and "Watson" etched into the surface. The 
project archaeologist located a map of Roxbury from 1885, which shows Sherwin School a short distance from the tenement (Eric Johnson, personal communication 2016). Census records from 1880 list the Watson family as residents of the property, which included a young boy to whom the slate could have belonged (Eric Johnson, personal communication 2016). As archaeologists, it is exciting to potentially link a long-forgotten piece of material culture with the individual who may have used it. We see this level of archival research as a model for good CRM.

In short, archival research holds exciting possibilities for archaeologists, yet embedded within so many archival documents are details about both sites and sociohistorical contexts that must be evaluated as objectively as possible. We turn now to a discussion of how archaeologists may draw on their training to approach archival research.

\section{APPLYING ARCHAEOLOGICAL THEORY AND METHOD TO ARCHIVAL RESEARCH}

Going blindly into a research site would be equally overwhelming for a researcher, regardless of whether the site in question was archaeological or archival. Just as archaeologists never go into the field without some amount of planning beforehand, we do not suggest conducting archival research without a similar degree of forethought. We argue that retooling various lessons from archaeological training would better equip an archaeologist when conducting archival research, resulting in stronger overall research results. In addition, we believe that archival research is vital to every archaeological project and should be considered a "best practice."

If you are considering archival research, we offer the following eight guidelines (for more research tips, see also Fowler and Crum 1999; Kirch and Rowan 2008; Schmidt 2011; Silverman and Parezo 1995; Society of American Archivists 2016; Vogt-O'Connor 1999):

1. Learn the landscape

2. Reach out to institutions

3. Draft a plan

4. Collect data

5. Secure all data

6. Follow up with contacts

7. Analyze and interpret data

8. Publish research results

We see these eight steps as fluid and cyclical in nature. As a research project continues, you might find yourself returning to many of these points as the landscape becomes further refined. With this said, it is important to point out that you should never see your archival research as being "done," meaning that it is impossible for you to say that you have turned over every stone. As in all research projects, we know that there may be only a limited amount of time set aside for archival research before you must head to the field or submit a report.

\section{Lessons to Apply before Visiting an Archive}

Learn the landscape. Archaeologists are trained to always think in terms of time, space, and scale. For the purposes of archival research, you should begin by establishing what institutions and individual researchers were involved in the research question at hand by working back through time. From here, you will likely begin to identify archives of significance, although it is important to note that key players change though time (Sullivan 1991). For example, when conducting research on the history of Massachusetts archaeology, Kirakosian began by compiling a list of the major publications in Massachusetts archaeology and then connecting those authors to their home institutions (Kirakosian 2014). While some institutions still maintained an important role in the archaeology of the state, other institutions that no longer conducted such research unexpectedly became promising locales for archival research. Assumptions should not be made about the potential importance of varying institutions and actors, while the potential for assumptions (and surprises) increases the farther back one goes in space and time. In addition, due to the fragmentary nature of archives, it is unlikely that you will find everything that you hope to know about a topic at any one given archive. For these and other reasons, you should look as broadly as possible.

To help facilitate research in this earliest phase, we have created a Google map of archives of archaeological interest. During this first phase, you should also be on the lookout for digital archives that can help guide your research process. ${ }^{1}$ Digital archives help you answer important questions without needing to then schedule an in-person visit to an archive. Although visiting an archive may be out of your reach due to budgetary or time constraintsdigital archives allow for research with minimal time and money spent. They can also help formulate new questions or help prioritize existing ones. For example, when Kirakosian was conducting dissertation research, she was able to access several digital archives that altered her understanding of key connections between several important actors in the history of Massachusetts archaeology (Kirakosian 2014). Had she not accessed these digital archives early in her dissertation research, her overall results would have differed and several ongoing research projects would not have commenced.

Reach out to institutions. Once you have established the key institutions that you believe have archival resources of interest to the project, you should reach out to them as soon as possible. Never just show up at the doorstep. Do this preferably via e-mail and include an introduction to your project and details about what you hope to access. By sending an e-mail, you have begun a record of your communication that will likely help you keep track of various details later (who you communicated with and when, contact information, whether there are materials there related to your research, etc.).

By reaching out to one institution months before she hoped to visit, Kirakosian got a lot of groundwork done before arriving. Museum staff members knew her research topic and had done some "digging" of their own to identify archival materials of interest. These were set aside awaiting her arrival. However, not every institution is able to welcome researchers. For example, Kirakosian reached out to an institution that was in the midst of renovations and hesitant about hosting a researcher. 
This direct approach works best with smaller institutions, as the sheer volume of researchers using larger collections generally prohibits staff from doing advanced searching on behalf of researchers or offering personalized assistance. In addition, larger institutions generally have guidelines on accessing collections all researchers must follow. To access collections at the British Library and the Bodleian Library at University of Oxford, Bauer-Clapp had to register for a reader's card, which must be obtained in person. She could not request materials in advance without the reader's card but could search the digital catalogs of each institution and make note of materials to request once on site.

After Kirakosian reached out to one institution, an employee was gracious enough to look through a small, unprocessed collection and send her some early twentieth-century field pictures. In addition, when conducting archival research at the Nantucket Atheneum, she learned that they were about to get all of their newspapers online. If she had not discussed her research project with a librarian, she might never have known this was going to happen in only a few months.

Draft a plan. After identifying and ideally reaching out to key institutions, you should draft a plan that includes the following key components: timeline, sampling strategy, tools needed, and institutional rules. Similar to the fact that archaeological sites are never be completely sampled, it is not possible to visit every archive that will likely have important information for a project. Not only will your research question impact decisions here, but time, distance, and budget will as well. For example, Kirakosian made the hard choice that she could (and should) visit only about half of the institutions that were on her wish list. After e-mailing some institutions, she determined that she would likely have minimal returns. She also eliminated those institutions that did not openly welcome a research visit.

Ultimately, you should ask what institutions must you visit and how long should a site visit be based on the amount of material there? Just as archaeologists make a plan for how long a Phase 1 , Phase 2, or Phase 3 project will take (based on how quickly a $1 \times 1 \mathrm{~m}$ unit can be excavated, for example) you can estimate how long it might take to review one linear foot of paperwork. If you are able to commit only one or two days of research at an institution, then prioritize what you want to access first, second, and so on. For example, when visiting the New York State Museum, Kirakosian knew that she needed to access the original field notes for several excavations, which became her priority. From there, she knew that there were also dozens of boxes of communication during one key archaeologist's tenure at the museum. These became her second priority.

This last point relates to sampling strategy. Since some archives are enormous, without a sampling strategy it would be like excavating a site with a spoon. With this said, Kirakosian applied her knowledge of strategic sampling. After confirming via e-mail and phone about the ways in which letters were organized at the New York State Museum (by year and then individual), she identified several key boxes that she wanted to see. Then she made a list of key people that the archaeologist in question communicated with about the given project (i.e., field crew, colleagues, landowners), so she was able to go directly to these files. Having all of this information saved countless hours because a strategy was determined before getting on site.
Similar to an archaeological excavation, part of drafting a plan for archival research includes bringing the right tools. One very important thing you should be sure of before visiting an archive is what types of materials are allowed while conducting research. Each archive that Kirakosian visited had different rules about how primary data could be gathered. For example, while one allowed her to bring a sheet-fed scanner, another allowed only a flatbed scanner. Scanners of any sort were not allowed at the New York State Museum archives room. Here only a camera and laptop could be used, and no bags and/or writing implements of any sort could accompany the researcher. She was also given a locker where all her additional personal items had to be stored while accessing archival materials. Scanners were not allowed at any of the institutions Bauer-Clapp visited, and the British Library's Rare Book Room did not allow cameras or any other digital imaging tools.

The need to plan continues, however, since bringing any electrical equipment, if allowed, is not as simple as it might seem. Extension cords and outlet splitters may come in very handy if electrical outlets are far away from a research space or there are limited outlets. Some research spaces may not have easy access to electrical outlets at all, so having laptops fully charged before arriving is also important. Keep in mind that these different rules can impact your timeline (e.g., can you use a sheet-fed scanner or flatbed scanner or camera). For example, Kirakosian was able to scan roughly one page per minute on her flatbed scanner, while her sheet-fed scanner could scan 20 single (or double-sided pages) per minute. Another important piece of information to know is whether you will have Wi-Fi access.

In addition to how quickly one can work through archival material, the length of the visit depends on how quickly researchers can access those materials. As discussed earlier, Bauer-Clapp was not allowed to request materials from the British Library or Bodleian Library until she obtained a reader's card at those institutions. Most materials she needed to access at the Bodleian Library had a 24-hour return time, meaning Bauer-Clapp needed to spend a minimum of two days on site regardless of the number of materials accessed. An institution's rules can also impact your budget, since the use of a copier can become incredibly expensive. Taking all of this into account is vital and must happen as early in the research planning process as possible.

You should also keep in mind that when making multiple trips to the same archive, the rules can change. Bauer-Clapp conducted dissertation research at the St. Helena Archives on three occasions-during the first two trips, she was allowed to take digital photographs of texts. On the third visit, digital photographs of some texts were no longer allowed. The archive is very small and remote and the collections policies are not posted online; she had no reason to suspect that the rules had changed until she pulled out her iPad to take an image and was told this was not allowed. At institutions without formal access policies, there may even be variation between staff members regarding what is and is not allowed by researchers.

\section{A Lesson to Apply while Visiting an Archive}

Collect data. This might sound simple enough, but the operative word is collect. Kirakosian had only a few days to conduct research at the Robert S. Peabody Museum and the New York State Museum, yet thousands of pages to review in this time. 
Instead of reading field notes or letters in depth, she scanned all the necessary field notes without even reading them. That would have slowed her down, especially given the fact that the handwriting on some letters was difficult to decipher. She continually reminded herself that the time for analysis is later. Similarly, in the field you might collect samples unsure if they will truly be significant in the end. You can only trust that they might be at the time and determine the full significance later. The goal is to get the largest amount of "potentially significant" information during the time allotted.

Bauer-Clapp, on the other hand, often needed to read materials more thoroughly and take notes on site, as scanning or taking digital images were not allowed at several institutions. In other words, the only data she would leave with was what she recorded on site. Imagine excavating an obviously fragile textile-the instant you remove it from the excavation unit, you know it will virtually disintegrate, so your data are limited to the detailed notes you can take while the textile is still in situ. In the Rare Book Room at the British Library, where digital images were not allowed, Bauer-Clapp found a particularly useful set of pages in a book the staff deemed too old for photocopies, so her only option was to type the text word-for-word on her laptop. Collecting data on site by reading and taking notes also required her to engage in more decision-making on site. If a particular set of documents did not seem as useful as hoped, she had to decide whether to keep reading or turn her attention elsewhere. This echoed the decision-making process during excavation, when an excavation unit may not yield many finds-do you keep digging in that area or open a new unit in another location? The data collection process requires constant adjustment in response to conditions on site as well as the data themselves.

Some practical concerns also apply when collecting data in a physical archive. Your physical comfort should also be considered, so that you can be sure to focus on the task at hand. For example, if you have a choice of where to sit, consider staying away from busy areas (e.g., conversations at the main desk, windows that may divert your attention, television sets within view, etc.). Also, a comfortable researcher is a productive researcher. If you are cold, warm, thirsty, or hungry, will you be able to focus? A few personal necessities that Kirakosian was always sure to bring included water, snacks/lunch (as allowed), petty cash, and pain relievers. Consider dressing in layers as well, since temperatures can fluctuate wildly in research facilities.

A research visit is also an excellent networking and general learning opportunity. Be gracious to everyone helping you at the host institution. It is understandable that they may want to know more about your project and to check in to see how things are going during your visit. Be sure to strike a careful balance here, since you may depend on them in key and unexpected ways later.

\section{Lessons to Apply after Visiting an Archive}

Secure all data. The same is true for archival data as it is for data collected at a site. Both are "fieldwork" with valuable data. Upon returning from the field, we are sure to check that storerooms are locked, tags are legible, and flotation samples do not mold. Upon returning from a day of archival research, all data should be backed up. Kirakosian also spent several hours after each day of archival research, organizing and renaming files as well. During this time, if any issue had been noticed, such as cor- rupt files or blurry images, she could have addressed this the next day perhaps, as opposed to discovering an issue after she left the research site entirely and it was too late. In fact, Kirakosian had issues while downloading images from her camera upon returning from one research site. Luckily these had been backed up and also not deleted from her camera. Having failed to do this would have resulted in the loss of a week's worth of research. When Bauer-Clapp was limited to taking handwritten notes, she took digital images of all notes at the end of each day, which served as a backup until she had time to type up the notes. When conducting research over multiple days, it was helpful to have the previous day's notes on hand, yet without the digital backup, that work would have been lost if she misplaced the notebook or spilled coffee on it during a break.

Follow-up with your contacts. Good research requires relationship-building. Don't bury your thanks in written acknowledgments, which can take years to be published and may never be seen by those acknowledged. Before leaving a research site, Kirakosian made a point to genuinely and directly thank everyone who offered assistance. Upon returning home from a research visit, a thank you e-mail was also sent right away. Doing this helped keep the lines of communication open as well. During these e-mails, Kirakosian also confirmed that nothing was still needed by the institution, such as a signed user agreement.

Analyze and interpret data. This step is likely the most timeconsuming steps in the process of conducting archival research. Just as lab analysis takes exponentially longer than the amount of time spent in the field, the same is true of archival research. Now that a great deal of potentially significant data is in hand, one must take the time to analyze and interpret this data. The time set aside for data analysis and interpretation depends entirely on the nature of the data and necessary level of analysis.

Publish research results. While this final step should go without saying, every archaeologist knows how much field data is never analyzed, interpreted, and/or published. Similar to the need to publish archaeological data, we see publishing archival data as an ethical imperative as well. Publishing these primary data sets makes these data available to other researchers who can then build on your research.

\section{CONCLUSION}

In this article, we argue that some amount of archival research is a necessary research component in most, if not all, archaeological research. However, this should also never be seen of as just a box to be checked off or a hurdle to overcome at the beginning of a project, so that the "real" archaeological work can begin. As many archaeologists know, archives offer necessary, and at times unexpected, context and can even guide a field or research project. Archaeologists should expect unique access and interpretive challenges with archival materials, given the fact that field notes, photographs, hand-drawn sketches, maps and floor plans, personal letters, and even data difficult to access anymore (e.g., audio files on obsolete media as well as punch cards and floppy disks) are so diverse, unique, and site-specific.

Since few archaeologists are trained archivists, the process of conducting archival research may seem daunting. Throughout this article, we have shared our approach to archival research 
that connects to elements of our archaeological training. Our experiences have shown us that when archaeologists approach archival research systematically, what we are able to learn about the human experience through time and space is enhanced.

In this same vein, we also urge archaeologists to employ best practices for their own materials, which might become part of an archive of future research interest. This includes keeping good records, backing everything up, always including descriptive information with your materials, including good metadata for anything that is electronic, and ensuring that all of your materials are dated and that you employ a meaningful and consistent naming system for all paper, photographic, and electronic files (Gina Rappaport, personal communication 2016).

\section{Acknowledgments}

First and foremost, we offer a special thanks to Sarah Herr for her patient guidance through this process. We also benefited greatly from detailed feedback from our anonymous reviewers. Eric Johnson and Gina Rappaport were both generous with their time and shared valuable thoughts and experiences on this topic. Finally, we thank Matthew Valletta for translating our abstract into Spanish.

\section{Data Availability Statement}

The archival data discussed here are published in Bauer-Clapp (2016), Bauer-Clapp and Perez (2014), and Kirakosian (2014).

\section{REFERENCES}

Averett, Erin Walcek, Jody Michael Gordon, and Derek B. Counts (editors) 2016 Mobilizing the Past for a Digital Future: The Potential for Digital Archaeology. Digital Press at the University of North Dakota, Grand Forks.

Bauer-Clapp, Heidi J.

2016 A Conflict of Interest? Negotiating Agendas, Ethics, and Consequences Regarding the Heritage Value of Human Remains. PhD dissertation, Department of Anthropology, University of Massachusetts Amherst, Amherst, Massachusetts. Accessible at http://scholarworks. umass.edu/dissertations_2/643/.

Bauer-Clapp, Heidi J., and Ventura R. Pérez

2014 Violence in Life, Violence in Death, Resiliency through Repatriation: Bioarchaeological Analysis and Heritage Value of Yaqui Skeletal Remains from Sonora, Mexico. In Bioarchaeological and Forensic Perspectives on Violence, edited by Debra L. Martin and Cheryl P. Anderson, pp. 171191. Cambridge Studies in Biological and Evolutionary Anthropology 67. Cambridge University Press, New York, New York.

Claassen, Cheryl A.

1995 Dogan Point and Its Social Context. In Dogan Point: A Shell Matrix Site in the Lower Hudson Valley, edited by Cheryl Claassen, pp. 65-78. Occasional Papers in Northeastern Anthropology 14. Archaeological Services, Bethlehem, Connecticut.

Cook, Terry

2001 Archival Science and Postmodernism: New Formulations for Old Concepts. Archival Science 1:3-24.

Council for the Preservation of Anthropological Records (CoPAR)

2016 Home page. Electronic document, http://copar.org/, accessed September 12, 2016.

Danielson, Elena S.

2010 The Ethical Archivist. Society of American Archivists, Chicago, Illinois. Dobreva, Milena, and Wendy M. Duff
2015 The Ever Changing Face of Digital Curation: Introduction to the Special Issue on Digital Curation. Archival Science 15:97-100.

Eastwood, Terry, and Heather MacNeil (editors)

2017 Currents of Archival Thinking. 2nd ed. Libraries Unlimited, Santa Barbara, California.

Eiteljorg, Harrison, II

1998 Archiving Archaeological Data in the Next Millennium. Special Issue on Information Ecosystems. CRM 21(6):21-23.

Foucault, Michel

1972 The Archaeology of Knowledge. Pantheon Books, New York.

Fowler, Catherine S., and Steven J. Crum

1999 Ethical Use of Anthropological Records. CoPAR Bulletin 10. Council for the Preservation of Anthropological Records, Reno, Nevada. Electronic document, http://copar.org/bulletin10.htm, accessed September 12, 2016.

Fowler, Don D., and Douglas R. Givens

1995 The Records of Archaeology. In Preserving the Anthropological Record, 2nd ed., edited by Sydel Silverman and Nancy J. Parezo, pp. 97-106. Wenner-Gren Foundation for Anthropological Research, New York.

Gero, Joan

1990 Facts and Values in the Archeological Eye: Discussion of "The Powers of Observation." In Powers of Observation: Alternative Views in Archeology, edited by Sarah M. Nelson and Alice B. Kehoe, pp. 113-119. Archeological Papers of the American Anthropological Association Number 2. American Anthropological Association, Arlington, Virgina. Huggett, Jeremy

2015 Challenging Digital Archaeology. Open Archaeology 1:79-85. Jackson, Jean $\mathrm{E}$

1990 "I Am a Fieldnote": Fieldnotes as a Symbol of Professional Identity. In Fieldnotes: The Makings of Anthropology, edited by Roger Sanjek, pp 3-33. Cornell University Press, Ithaca, New York.

Ketelaar, Eric

2002 Archival Temples, Archival Prisons: Modes of Power and Protection. Archival Science 2:221-238.

Kirakosian, Katharine Vickers

2014 Curious Monuments of the Simplest Kind: Shell Midden Archaeology in Massachusetts (1868-2008). PhD dissertation, Department of Anthropology, University of Massachusetts Amherst, Amherst, Massachusetts. Electronic document, http://scholarworks.umass.edu/ dissertations_2/12/, accessed June 22, 2017.

Kirch, Gesa A., and Liz Rowan (editors)

2008 Beyond the Archives: Research as a Lived Process. Southern Illinois University Press, Carbondale.

McKemmish, Sue

2001 Placing Records Continuum Theory and Practice. Archival Science 1:333-359.

Means, Bernard K

2013a (editor) Shovel Ready: Archaeology and Roosevelt's New Deal for America. University of Alabama Press, Tuscaloosa.

2013b Introduction: "Alphabet Soup" and American Archaeology. In Shovel Ready: Archaeology and Roosevelt's New Deal for America, edited by Bernard K. Means, pp. 1-20. University of Alabama Press, Tuscaloosa.

Poole, Alex $\mathrm{H}$

2015 How Has Your Science Data Grown? Digital Curation and the Human Factor: A Critical Literature Review. Archival Science 15:101-139.

Roosevelt, Christopher H., Peter Cobb, Emanuel Moss, Brandon R. Olson and Sinan Ünlüsoy

2015 Excavation is Digitization: Advances in Archaeological Practice. Journal of Field Archaeology 40(3):325-346.

Schmidt, Laura

2011 Using Archives: A Guide to Effective Research. Society for American Archivists, Chicago. Electronic document, http://www2.archivists.org/ sites/all/files/UsingArchives_Final.pdf accessed September 21, 2016.

Schwartz, Joan M., and Terry Cook

2002 Archives, Records, and Power: The Making of Modern Memory. Archival Science 2:1-19. 
HOW-TO SERIES

Shackel, Paul

1992 Probate Inventories in Historical Archaeology: A Review and Alternatives. In Text-Aided Archaeology, edited by Barbara J. Little, pp. 205-215. CRC Press, Boca Raton, Florida.

Silverman, Sydel

1995 Introduction. In Preserving the Anthropological Record, 2nd ed., edited by Sydel Silverman and Nancy J. Parezo, pp. 1-14. Wenner-Gren Foundation for Anthropological Research, New York.

1999 Why Preserve Anthropological Records? CoPAR Bulletin 1. Council for the Preservation of Anthropological Records, Reno, Nevada. Electronic document, http://copar.org/bulletin1.htm, accessed September 12, 2016.

Silverman, Sydel, and Nancy J. Parezo (editors)

1995 Preserving the Anthropological Record. 2nd ed. Wenner-Gren Foundation for Anthropological Research, New York.

Society of American Archivists

2016 Visiting an Archives. Electronic document, http://www2.archivists.org/ usingarchives/visitinganarchives, accessed September 15, 2016.

Sullivan, Lynne

1991 Museum Records and the History of Archaeology. Bulletin of the History of Archaeology 1(2):4-12.

Thomassen, Theo

2001 A First Introduction to Archival Science. Archival Science 1:373-385.

Tourney, Michele M.

2003 Caging Virtual Antelopes: Suzanne Briet's Definition of Documents in the Context of the Digital Age. Archival Science 3:291-311.

Trace, Ciaran B.

2002 What Is Recorded Is Never Simply "What Happened": Record Keeping in Modern Organizational Culture. Archival Science 2:137-159.

Vogt-O'Connor, Diane

1999 Tips on How to Research in an Archives. Special Theme Issue: Archives at the Millennium. CRM 22(2):44-45.
Williams, Caroline

2006 Managing Archives: Foundations, Principles and Practice. Chandos Publishing, Oxford.

Ziegenbein, Linda M.

2013 Inhabiting Spaces, Making Places: Creating a Spatial and Material Biography of David Ruggles. PhD dissertation, Department of Anthropology, University of Massachusetts Amherst, 217 Machmer Hall, 240 Hicks Way, Amherst, Massachusetts.

\section{NOTE}

1. Inspired by the Council for the Preservation of Anthropological Records (CoPAR) and their Guide to Anthropological Fieldnotes and Manuscripts in Archival Repositories and Directory of Ethnographic Archives (CoPAR 2016), we have created these more targeted resources, which focus only on archives of archaeological interest. The authors encourage you to add points on the Google map and submit more links to known digital archives.

\section{AUTHORS INFORMATION}

Katie Kirakosian and Heidi Bauer-Clapp Anthropology Department, University of Massachusetts Amherst, 217 Machmer Hall, 240 Hicks Way, Amherst, MA 01003, USA (kvkirako@anthro.umass.edu; hbauercl@anthro.umass.edu) 